\title{
Lygia Fagundes Telles, “A Maior Escritora Brasileira Viva”, e a Perspectiva da Velhice
}

\author{
Lygia Fagundes Telles, "La Más Grande Escritora Brasileña Viva" y la \\ Perspectiva de la Vejez
}

Lygia Fagundes Telles, "The Greatest Brazilian Woman Writer Alive",
and the Perspective of the Old Age

Yls Rabelo Câmara ${ }^{1}$

\begin{abstract}
Resumo
Nesse artigo tratamos da "Dama da Literatura Brasileira", da "Maior Escritora Brasileira Viva", da quase centenária Lygia Fagundes Telles, analisando sua perspectiva da velhice por meio da análise de três de suas personagens velhas mais emblemáticas, protagonistas de dois contos e de um romance de sucesso da autora. Para tanto, nessa revisão de literatura, ancoramos nossas considerações em investigadores basilares da área como Beserra (2011a; 2011b), Prazeres (2015) e Sperandio (2009). Concluímos que Lygia Fagundes Telles, por seu lastro e legado premiados nacional e internacionalmente, merece figurar nesse número da Revista Relacult, dedicado a essas mulheres-autoras latino-americanas que são videntes e são sensíveis na arte e na cultura dos que falamos as línguas ibéricas no continente americano.
\end{abstract}

Palavras-chave: Escritoras Brasileiras; Literatura Brasileira; Lygia Fagundes Telles; Personagens Idosas; Velhice.

\section{Resumen}

En este artículo, tratamos de la "Dama de la literatura brasileña", de la "Más grande escritora brasileña Viva", de la casi centenaria Lygia Fagundes Telles, analizando su perspectiva de la vejez a través del análisis de tres de sus personajes viejas más emblemáticas, protagonistas de dos cuentos y de una novela exitosa de la autora. Por lo tanto, en esta revisión de literatura, anclamos nuestras consideraciones sobre estudiosos como Beserra (2011a; 2011b), Prazeres (2015) y Sperandio (2009). Concluimos que Lygia Fagundes Telles, por su lastre y legado galardonados a nivel nacional e internacional, merece ser presentada en este número de la revista Relacult, dedicada a estas autoras latinoamericanas que son videntes y sensibles en el arte y en la cultura de los que hablamos los idiomas ibéricos en el continente americano.

Palabras clave: Escritoras brasileñas; Literatura brasileña; Lygia Fagundes Telles; Personajes de edad avanzada; La vejez.

\begin{abstract}
In this article, we deal with the "Lady of Brazilian Literature", the "Greatest Brazilian Woman Writer Alive", the almost centenary Lygia Fagundes Telles, analyzing her perspective of the old age through the analysis of three of her most emblematic old women characters, protagonists of two short stories and a successful novel written by this author. Therefore, in this literature review, we anchor our considerations on important scholars such as Beserra (2011a; 2011b), Prazeres (2015) and Sperandio (2009). We conclude that Lygia Fagundes Telles, for her ballast and national and international award-winning legacy, deserves to be presented in this issue of Relacult Journal, dedicated to those Latin-American women authors who are visionaries and sensitive in art and culture based on our Iberian languages in the American continent.
\end{abstract}

\footnotetext{
${ }^{1}$ Pós-Doutora em Educação, Doutora e Mestra em Filologia Inglesa; Universidade Estadual do Ceará; Fortaleza, Ceará, Brasil; yls.camara@uece.br.
} 
Keywords: Brazilian Women Writers; Brazilian Literature; Lygia Fagundes Telles; Elderly Women Characters; Old Age.

\section{Considerações Iniciais}

A Revista RELACULT, nesse número, traz o dossiê "Ser vidente e ser sensível: mulheres-autoras, arte e cultura na América Latina”. Em se tratando de literatura produzida por mulheres latino-americanas, o nome de Lygia Fagundes Telles surge fulgurante dentre outros igualmente exponenciais como os de Isabel Allende (chilena), Teresa Cárdenas (cubana), Guadalupe Nettel (mexicana), Selva Almada (argentina), Laura Restrepo (colombiana), Cristina Peri Rossi (uruguaia), Teresa de la Parra (Venezuela) e Gioconda Belli (Nicarágua) autoras atuais; na maioria, feministas.

Apesar de atual, ainda que não seja mais tão prolífera como outrora, Telles não se considera uma feminista, mesmo que sua escritura seja visceralmente centrada no feminismo em algumas obras. Considerada há mais de dez anos como a "Maior Escritora Brasileira Viva", referência basilar na literatura, na arte e na cultura do nosso país, cremos que ela representa condignamente nossas escritoras nacionais pretéritas e contemporâneas pela excelência de seu trabalho e pelo lastro literário que nos lega, onde contos e romances de sucesso a eternizam com as mais altas condecorações do mundo das letras.

Aos seus noventa e sete anos, é, desde que começou a publicar e se tornar conhecida pelo grande público, há mais de setenta anos, uma escritora sintonizada com a mulher de seu tempo. Por conseguinte, sua obra vem plasmando a mulher velha desde que ela começou a sentir os sinais da finitude. Personagens idosas como Maria Emília, de Sr. Diretor; Maria Leonor, de Boa noite, Maria e Rosa Ambrósio, de As Horas Nuas, estão entre as mais conhecidas por seus leitores, que se identificam com elas e com os problemas tão humanos e tão tangíveis que elas apresentam e representam.

Nesse trabalho, avaliamos a velhice pelo prisma dessas três protagonistas idosas dessa escritora ímpar. Contudo, antes de adentrarmos o escopo desse levantamento bibliográfico, traçamos algumas linhas sobre Lygia Fagundes Telles e sua escritura, que a distingue e destaca dentre as nossas escritoras mais emblemáticas e lhe confere o título de "Dama da Literatura Brasileira".

\section{Em Rápidas Pinceladas, Lygia Fagundes Telles}


Telles é a consagrada autora de obras exitosas que não raro são traduzidas para idiomas tão díspares como chinês, sueco, polonês e tcheco - além de inglês, espanhol, francês, italiano e alemão (SANTOS, 2012). Ganhadora dos mais importantes prêmios literários nacionais e internacionais - como o Arthur Azevedo (1958), o Jabuti (em quatro ocasiões distintas - 1966, 1974, 1996 e 2001) e o Juca Pato (2008) - galardoada com o Prêmio Camões em 2005 e a única dentre as nossas literatas a ter sido indicada ao Prêmio Nobel de Literatura, em 2016, LFT disseca a alma humana com sua escritura impregnada de simbologia, profundidade e, ao mesmo tempo, simplicidade.

Sua verve literária foi-lhe incentivada desde a infância pela mãe, uma pianista não profissional, e pelo pai - advogado, promotor e juiz de direito. Crescendo entre babás que lhe contavam histórias de assombração, assim como lendas do nosso folclore, acostumou-se desde cedo a transferir essas histórias e lendas para seus escritos, que a princípio eram lidos nas reuniões familiares e que resultaram na publicação de seu primeiro livro, Porões e Sobrado (1938), às expensas paternas, em uma tiragem de mil exemplares, quando ela tinha quinze anos de idade.

Contudo, conforme Viana (2010), sua estreia oficial deu-se com a publicação de Praia Viva, em 1944 - uma coleção de dez contos que ela dedicou a Cecília Meireles e Monteiro Lobato, suas duas grandes referências primeiras. Ainda segundo Viana (2010), essas duas coletâneas de contos iniciais são consideradas por ela como uma espécie de ensaio para o seu posterior ofício de escritora, "livros mortos", que ela não computa em seu legado. A razão pela qual assim se explica, de acordo com Martins (2015), é porque seus conteúdos são incipientes, "ginasianos".

Aos dezoito anos e já cursando Direito na Faculdade de Direito do Largo de São Francisco, Lygia destacava-se dos colegas pelo fato de ser uma das seis alunas no meio de mais de cem rapazes na sala de aula; das raríssimas colegas, destacava-se pela beleza. Contudo, sua formosura não repousava apenas no físico, mas também e principalmente, em sua inteligência aguçada, que encantava os amantes da Literatura que, juntamente com ela e com exponenciais de nossas letras como Oswald de Andrade e Mário de Andrade, além de críticos literários e jovens intelectuais, se reuniam em saraus e rodas literárias universitárias nos sofisticados cafés, restaurantes e livrarias paulistanos dos anos 1940-1950 para debaterem sobre a arte das palavras.

À luz de Lucena (2007), naquele tempo, a cidade de São Paulo oferecia uma arquitetura e um estilo de vida europeus, esmerando-se pela elegância que agradava a elite advinda dos barões do café. Telles, frequentadora habitual desses ambientes refinados, tornara-se conhecida 
paulatinamente. A tal ponto Telles é vinculada a São Paulo que suas obras normalmente têm essa cidade como cenário, onde a classe média, à qual ela sempre pertenceu, é retratada em seu cotidiano (SPERANDIO, 2009).

Além da faculdade de Direito, cursou também Educação Física - dois cursos essencialmente masculinos. Assim como nas profissões que escolhera, o fato de ser escritora em uma época na qual o Brasil ainda não havia passado pela segunda onda do feminismo, dificultava ainda mais seu labor, já que não era muito comum que uma mulher exercesse livremente essas improváveis profissões - marcadamente masculinas - nem deitasse ao papel, de maneira comercial, os frutos de sua subjetividade. Suas contemporâneas tiveram as mesmas dificuldades que ela nesse sentido, mas nem todas tiveram a sua resiliência.

Fanini (2010) explica que Lygia concluiu a faculdade de Direito em 1946, quando o mundo vivia uma crise existencial sem precedentes, passando-se a temer uma terceira e última guerra mundial após o ocorrido em Hiroshima e Nagazaki um ano antes - quando, a partir de então, deu-se início à Guerra Fria entre as duas maiores potências econômicas mundiais, polarizadas entre os Estados Unidos (capitalista) e a União Soviética (socialista).

Já na década de 1950, ela alcança a maturidade como escritora, mas é na década de 1970 que o salto qualitativo de sua obra atinge o grande público e vários de seus livros são transformados em novelas televisivas e peças de teatro, atravessando fronteiras e sendo acolhidos nos mais distantes rincões do planeta. Naquele momento, o nome de Lygia Fagundes Telles já era bastante conhecido e aludia a uma artista em incessante processo de criação.

Interessante é o fato de que mesmo exercendo o ofício de procuradora no Instituto de Previdência do Estado de São Paulo por três décadas, conforme Viana (2010), a autora não tenha descuidado jamais de sua produção literária. Sua veia literária e o legado que nos deixa a capacitaram para tornar-se a terceira mulher a adentrar a Academia Brasileira de Letras, ocupando a cadeira $\mathrm{n}^{\circ} 16$ em 1987 (cinco anos após haver sido eleita), cuja vaga pertencera antes a Pedro Calmon, sob o patronato de Gregório de Matos (VIANA, 2010). Interessantemente, segundo Fanini (2010), Calmon sempre se opusera à presença feminina na ABL, apesar de haver votado em Dinah Silveira de Queiroz quando essa concorrera e ganhara, em 1981.

Apesar de quase centenária atualmente, Lygia Fagundes Telles ainda se mantém lúcida, ainda que não mais se dedique ao afã de escrever como antes. Seu estilo, único e inconfundível, imprimiu uma marca indelével entre seus pares e a eternizou como uma das maiores escritoras brasileira de todos os tempos. Sobre sua escrita e peculiaridades quanto à arte de trabalhar com as palavras, tratamos a seguir. 


\section{A Escritura Lygiana}

Seguindo o conceito de Roland Barthes (1977), de que a escritura é a escrita do autor, a lygiana, em particular, apresenta características próprias e que distinguem essa autora de todas as outras nossas - sejam elas pretéritas, sejam elas atuais.

Seu estilo é visceral. Seus temas têm sempre muito de humano em seu cerne: tratam sobre a sexualidade em sentido macro e a homossexualidade feminina em sentido micro, assim como o preconceito racial, a fragilidade humana, os desencontros, a desestruturação da família patriarcal e os inevitáveis conflitos familiares dela resultantes, a ambiguidade, a busca pelo sentido da vida, a condição feminina no mundo pós-moderno, o abandono, o medo, solidão, a loucura, a velhice e a morte - dentre outros (BESERRA, 2011a; SANTOS, 2012; SPERANDIO, 2009).

Apesar da densidade dos temas por ela abordados, o estilo literário de Lygia é leve, ao mesmo tempo que contundente quando necessário. A linguagem que utiliza é coloquial, direta, com o campo semântico muito próximo ao dos leitores, e impregnada do fluxo de consciência que, para Viana (2010), traz para o plano da escrita os abalos psíquicos vividos pelas personagens. De acordo com essa teórica, como Telles é uma escritora de origem modernista, normalmente associada ao período pós-Segunda Guerra Mundial - quando o Existencialismo sartreano, o Expressionismo e o Surrealismo deram a tônica das Artes - ela vem explorando, desde o início de sua carreira literária, a expressão do inconsciente, juntamente com a retratação de temas que por muito tempo foram considerados tabu (como a repressão da libido, por exemplo), somados a momentos de reivindicação feminista que foram sendo gradativamente evidenciados em seus escritos.

Uma vez que crescera em uma época de transformações sociais como o foi a Era Vargas, Lygia transferiu para a sua obra muito do que vivenciara. Assim era a Geração pós-45, conforme Martins (2015): um grupo de literatos que reagia contra o Modernismo e suas experiências literárias revolucionárias dos anos 20 e 30. Seus coetâneos foram, àquela época, à luz de Viana (2010): Autran Dourado, Nélida Piñón, Otto Lara Resende, Fernando Sabino e Clarice Lispector, dentre muitos outros. Apesar de não se distanciarem das questões sociais, centraram-se nas angústias humanas mais internas, em suas incertezas e contradições. 
Devido à influência de seu gosto literário e de sua infância impregnada pelo fantástico e pelo maravilhoso, pelo onírico e pelo sobrenatural, sua narrativa mergulha no interior e no exterior das personagens, dividida entre o real e o irreal, focada no duplo. Além disso, a tensão crescente e que leva a um clímax inesperado é um elemento marcante de sua obra. Suas narrações labirínticas prendem a atenção do leitor e, não raro, utilizam-se do Fenômeno Phi, deixando o final em suspenso, em aberto, à conclusão do público. LFT utiliza-se igualmente da intertextualidade e da metanarratividade e sua estrutura narrativa é inovadora também nesse sentido: nela encontramos, além do tom intimista e do monólogo interior, o discurso indireto livre e o diálogo, típicos de Virginia Woolf e Clarice Lispector (GOMES, 2015; MARTINS, 2015).

Apesar de não se auto rotular como feminista e nem de aceitar ser considerada como tal, sua escritura orbita em torno do universo feminino, como já mencionado, com maior ou menor grau de engajamento político e social. A maioria de suas personagens emblemáticas são mulheres transgressoras e que desafiam o patriarcado; são complexas e refletem as mudanças ocorridas na sociedade (GOMES, 2015). Para além disso, as narradoras são especialmente importantes em sua obra, pois a autora empresta-lhes humanidade para narrar, em primeira pessoa, o intimismo e a introspecção tão típicos do Existencialismo e que está presente maciçamente em seus escritos. Essas narrativas especialmente povoadas por personagens femininas, são, não raro, conforme Viana (2010), autodiegéticas, heterodiegéticas e oniscientes, mesclando fluxo de consciência e fluxo de memória.

As personagens masculinas, em contrapartida, não têm essa mesma definição de contornos. Além do mais, para Beserra (2011a), as figuras masculinas exemplares são inexistentes, cabendo às mulheres essa incumbência. A bem da verdade, a inexistência da figura paterna e que culmina na desestrutura familiar é uma das características mais identificativas da autora em sua vasta obra. Como sua escritura é memorialística, também segundo Beserra (2011a), Lygia pode ter essa concepção advinda de sua relação com os pais, especialmente com o pai, que faleceu cedo, depois de haver se distanciado dela e de sua mãe com a separação. Esse homem influenciou nossa autora até mesmo na presença da cor verde em vários de seus trabalhos. Essa era a cor favorita dele e aparece em "Antes do Baile Verde", "Venha Ver o Pôrdo-sol", "O Menino", "Natal na Barca" e "Verde Lagarto Amarelo", entre tantos outros contos.

Telles, segundo Viana (2010), destaca-se, sobretudo, por ser uma escritora que prima pela prosa urbana (retratando normalmente a capital paulista, mas também outros grandes centros urbanos). A classe média é por ela retratada em contos e romances sem distinção. No que a esses gêneros se refere, a autora iniciou sua trajetória como escritora de contos, depois 
passou aos romances, mas sem prescindir jamais dos contos. O poema, contudo, nunca foi um gênero pelo qual tenha se inclinado, apesar de haver sido sempre uma amante do verso, a partir da educação esmerada que tivera.

Podemos resumir o conjunto de sua obra nas seguintes publicações, de acordo com Viana (2010):

a) Romances: Ciranda de Pedra (1954), Verão no Aquário (1963), As Meninas (1973), As Horas Nuas (1989);

b) Coleções de Contos: Praia Viva (1944), Cacto Vermelho (1949), Histórias de Desencontro (1958), Histórias Escolhidas (1964), O Jardim Selvagem (1965), Antes do Baile Verde (1970), Seminário dos Ratos (1977), Filhos Pródigos (1978), Mistérios (1981), A Noite Escura e Mais Eu (1966) e Invenção e Memória (2000).

Merecem destaque também obras outras, que têm muito de memorialístico e de autobiográfico em si: A Disciplina do Amor (1980), Durante Aquele Estranho Chá (2002) e Conspiração de Nuvens (2007). Nelas, LFT explora a experiência pessoal e a imaginação, resignificando o passado (VIANA, 2010).

Em resumidas palavras: seja com romances, seja com contos, Lygia Fagundes Telles destaca-se por seu estilo inspirador próprio e que lhe garante recepção entusiasmada por parte do público e da crítica, além de premiações - as mais altas condecorações as quais um escritor pode almejar. Ultimamente, muito também devido à fase da vida na qual se encontra, LFT temse dedicado a escrever acerca da velhice e de tudo o que a ela concerne.

Sobre a velhice na obra lygiana, especialmente por meio de três de suas personagens velhas, tratamos a seguir.

\section{A Velhice Refletida em Três Personagens Idosas Lygianas}

Apesar de o envelhecimento ser a penúltima etapa da existência, comum a todos os seres vivos antes da morte, no que concerne aos seres humanos, ele é, à luz de Beserra (2011b), muito mais devastador para as mulheres do que para os homens por significar a perda da capacidade de sedução e, principalmente, de procriação.

Conforme Viana (2010) e Gomes (2015), por ser uma escritora que faz uso da representatividade em sua obra, as narrativas de Telles vêm plasmando, geração após geração, as inúmeras fases da vida pelas quais a autora tem passado, como já dito, pontilhadas por oscilações entre o mundo interior e o mundo exterior, levando a tensão do enredo para dentro 
das personagens e explorando os sentimentos que daí brotam em forma de fluxo de consciência e de monólogos interiores.

Por ser uma mulher que já vislumbra seu centenário dentro de três anos, Lygia Fagundes Telles vem retratando em suas obras a figura da velha há mais de quarenta anos, desde os anos 1970, sua década de ouro em termos literários, coincidentemente o momento histórico no qual as brasileiras testemunharam mudanças sociais significativas e que trouxeram câmbios importantes para suas vidas, a saber: o divórcio, a pílula anticoncepcional, maior liberdade sexual, os discursos em prol do aborto e maior inserção laboral.

Em linhas gerais, suas personagens femininas, independentemente da idade, têm seus dramas relacionados às dores de se viver em uma sociedade machista, preconceituosa e excludente (PRAZERES, 2015). Sem embargo, ao destacar as idosas em sua obra, LGT amplia a discussão em torno da mulher ao lhe buscar um lugar na sociedade que contemple sua dignidade, suas limitações e sua sexualidade.

Souza (2010) defende que o corpo feminino sempre foi tradicionalmente educado para ser belo. À mulher coube o papel socialmente construído da sedutora, da delicada, da pura, da formosa. Com tantos recursos para o embelezamento artificial à disposição daqueles que não nasceram agraciados pela beleza, a culpa pelo déficit de formosura recai sempre sobre o sujeito.

A velhice nem sempre é bela. Portanto, o envelhecimento feminino não raro vem acompanhado de dor emocional pela beleza perdida e que jamais será recuperada, assim como pelas limitações físicas e cognitivas que aumentam exponencialmente à medida que a mulher envelhece. Em uma sociedade regida pela égide do belo, uma velha, especialmente uma velha sem os atrativos de outrora, sente-se deslocada e rejeitada. Trava-se, então, a luta entre o corpo desejável e o corpo que inexoravelmente envelhece.

Se as marcas do tempo no corpo das mulheres são um tabu, muito mais o é a ideia de que uma mulher velha tenha vida sexual, uma vez que normalmente se associa o conceito de sexualidade ao conceito de fertilidade (SOUZA, 2010). Esse é o ponto fulcral que une as três protagonistas lygeanas sobre as quais discorremos a seguir: Maria Emília, em Senhor Diretor (1977), Maria Leonor de Bragança, em Boa noite, Maria (1998) e Rosa Ambrósio, em As Horas Nuas (1989).

\subsection{Maria Emília, em Senhor Diretor}

A protagonista do conto "Senhor Diretor" (pertencente à coletânea Seminário dos Ratos, publicada em 1977) é Maria Emília, uma professora paulista aposentada de sessenta e dois anos, virgem, ressentida com a libertinagem que crê ocupar os jovens dos anos 1970 e com a liberdade 
sexual conquistada tardiamente por algumas de suas poucas amigas na mesma faixa etária que a dela. Ter chegado à velhice sem ter desfrutado da vida repercute na personagem em forma de impotência, inveja, passividade, exasperação, medo e despeito. Percebemos nela o sofrimento de uma mulher que se sente inadequada, não pertencente socialmente e não desejada sexualmente; uma mulher que o tempo e a vida ressecaram e amarguraram (CÂMARA; CÂMARA, 2018).

Marcada pelo estigma de não ter se casado, de não ter tido filhos, de ser uma velha que jamais conheceu os prazeres carnais, Maria Emília desenvolve um forte sentimento de incompletude e de solidão que sabe que jamais será sanado. Naquele dia faria aniversário, mas estaria sozinha, sem ter com quem comemorar, já que prescindira da presença das amigas e dos sobrinhos - as únicas pessoas que lhe restavam de seus círculos sociais. É quando têm lugar os acontecimentos que a levam a escrever uma carta ao diretor de um jornal, reclamando da imoralidade que invadira o Brasil e que ela era obrigada a testemunhar sem aprovar.

Idealizando o que iria escrever, suas ideias verborrágicas, entremeadas de angústias pessoais e de carências represadas, escapam-lhe em torrente, mal aproveitadas pelas interferências de seu fluxo de consciência - tal como sua vida, que lhe escapou sem que ela dela se apropriasse a contento. Severa com seu próprio discurso na carta, Maria Emília corta parte do que necessita falar com a intensidade que lhe apetece para que não soe vulgar nem rancorosa - ambígua e, ao mesmo tempo visceral: duas características da narrativa lygiana (FERREIRA, 2014).

Nesse sentido, a carta, que tão urgentemente quer escrever e enviar ao diretor do jornal, se parece à página não escrita de um diário à guisa de catarse, um "monólogo ressentido" como o define Pedra (2010), e que, malgrado seu, queda inconclusa, apenas com o destinatário "Sr. Diretor" e nada mais além disso do que reticências.

Entre Maria Emília e Maria Leonor de Bragança, a protagonista do conto que analisamos a seguir, há um hiato de vinte e um anos entre ambas as publicações, tempo em que as ideias feministas, antes censuradas pela ditadura militar imperante no Brasil de então, germinaram e eclodiram em comportamentos mais liberais em um país já bastante mais permeável à liberdade sexual, sem tantos preconceitos como outrora, como se de uma maioridade plena se tratasse.

\subsection{Maria Leonor, em Boa noite, Maria}

Nesse conto (que faz parte da à coletânea A Noite Escura e Mais Eu, publicada em 1995), Telles trata de temas polêmicos como o empoderamento da velha diante do sexo e a eutanásia. Maria Leonor de Bragança tem sessenta e cinco anos e inicia um relacionamento de 
um ano com um estrangeiro, Julius Fuller, alguns anos mais jovem do que ela. Rica e fina, por ter ascendência burguesa, e solitária, apesar dessa condição privilegiada, a protagonista carioca busca no companheiro uma forma de aplacar sua carência através de uma amizade especial e desinteressada e que ele, ao final, lhe pratique a eutanásia, livrando-a de uma vida vegetativa e de uma morte agônica e solitária, uma vez que ela está seriamente enferma (SILVA et al., 2014). Maria Leonor é cônscia de que não está no padrão físico desejado pelos homens e tampouco o quer; isso é o que menos lhe interessa nesse momento de sua vida, com um quadro clínico irreversivelmente e avançando para o pior. Então, em vez de amargurar-se, como o fez Maria Emília em Sr. Diretor, quer aproveitar o tempo que lhe resta para ser feliz e morrer sem dor (LIMA, 2013).

Em Boa noite, Maria “[...] predominam o tempo psicológico e o discurso indireto livre, onde ora se encontra a voz do narrador em terceira pessoa, ora a voz da protagonista através do monólogo interior, com as divagações e devaneios de Maria" (Silva et al., 2014, p. 96). O ambíguo, o metafórico e o ambivalente estão igual e marcadamente presentes, sem contar com os símbolos lygeanos. Até o título do conto é sugestivo: evoca-nos despedida, noite, escuridão e fim de um ciclo. Os dois se conhecem em um aeroporto, onde encontros e despedidas (às vezes para sempre) ocorrem. O longo túnel que atravessam juntos ao saírem do aeroporto, no táxi, nos remete à longa existência de Maria Leonor e o mar que se vê de seu apartamento, para onde os dois vão, nos leva à fonte primeira da vida e onde tudo termina; a imagem da barca que divisam no mar nos faz lembrar a morte, com Caronte a nos cobrar a travessia. Em resumo, esses elementos têm um denominador comum: representam a longa existência da personagem e a morte que se aproxima (CÂMARA; CÂMARA, 2018).

Para além disso, é tão patente a dualidade que Telles empresta a esta obra que não sabemos ao certo, pela narrativa, se este amante-amigo realmente existe ou se é fruto da imaginação da protagonista, ou ainda se é alguém que existe, mas em um plano espiritual distinto e paralelo ao dela, como explicam Silva et al. (2014). Conforme Câmara e Câmara (2018), suas características físicas também despertam a atenção do leitor para o dúbio presente nele. Seria um ser celestial e etéreo ou um enviado das trevas pronto a realizar o último desejo de sua amada? O próprio Julius diz ser portador de dupla nacionalidade e implanta essas e outras dúvidas instigantes no público leitor e que dão vazão a um sem fim de questionamentos. Havia tido muitas ocupações laborais e é de se estranhar que as tenha tido em uma única vida e que tenha uma força física incomum e incompatível com sua idade.

Em suma, essa é uma história de amor e morte, capitaneada por Eros e Tânatos (LIMA, 2013; FERREIRA, 2014): por um lado, a pulsão de vida, com o amor inesperado; por outro, a 
necessidade de morrer antes que viver se torne um fardo insuportável. Mais do que isso, essa é também a história de uma mulher que é dona de seu próprio destino, que controlou sua vida e que quer também controlar sua morte. Maria Leonor sempre foi uma mulher independente e não seria diferente em seus últimos dias.

Alguns anos antes da publicação desse conto, LFT havia publicado seu quarto e último romance escrito até agora, As Horas Nuas (1989), que tem como protagonista uma atriz decadente, depressiva e alcoólatra, que não aceita a velhice nem o ocaso de sua carreira e tem como metas a escrita de um livro de memórias e o retorno triunfante aos palcos. Dentre as protagonistas de todos os seus quatro romances (Ciranda de Pedra - 1954, Verão no Aquário - 1963, As Meninas - 1973 e As Horas Nuas - 1989), essa é a única de meia-idade, desencantada com a abertura política dos anos 1980, imediatamente pós-ditatorial, e com os dilemas de fim do século.

\subsection{Rosa Ambrósio em As Horas Nuas}

Seu nome é Rosa Ambrósio e não é à toa - como nada é à toa na escrita lygiana: a sexagenária Rosa já não é a mesma flor de outrora - viçosa, bela e delicada: está velha, melancólica e decadente; é agora uma mulher que envelhece abandonada e que se nega a aceitar os rumos que sua vida tomou (BESERRA, 2011b). Rosa fenece longe da seiva que sempre a alimentou: a fama, os palcos e os aplausos. Distante está também da ambrosia que com os deuses do teatro se banqueteou e que dá origem ao seu sobrenome: hoje colhe os frutos amargos de uma vida vivida pela metade.

Com ela moram a empregada Dionísia e o gato Rahul (com "H de homem") no apartamento onde ela passa os dias relembrando os dias glamorosos de um passado já distante. Neste par que a accompanha, destaca-se Rahul: um gato "memorialista e agnóstico", castrado e que, como bem descreve Beserra (2011a), tem a consciência da morte, além da memória de todas as suas vidas passadas. Ademais de Rosa, ele também é um dos narradores, mas com um diferencial: têm onisciência, dialoga com o pretérito e com personagens já mortas, uma vez que está reencarnado e é dotado também de clarividência. Ambos os narradores ocupam corpos que não lhes apetecem: Rahul, porque não queria estar metamorfoseado; Rosa, porque queria seguir jovem, bela, desejada e ovacionada.

Nesse momento de reavaliação existencial, o que busca essa atriz sem palcos é desnudarse, reconectar-se com quem ela já foi, fugindo de quem é na atualidade; bebe, e quanto mais bebe, mais estranhamente lúcida fica e maior vazio encontra dentro de si. Em sua narrativa, 
labiríntica, incentivada pelo álcool em demasia, mescla cenas da vida real com as das heroínas que representou no teatro, resultando ambíguo o seu discurso - bem ao estilo de Telles.

Viúva de Gregório, professor universitário que se suicidou após ser severamente torturado pela ditadura e a quem ela traía com seu jovem amante e secretário Diogo (que a abandonou depois de uma violenta discussão tempos depois), mãe de Cordélia (uma "ex-futura tenista" obcecada por homens muito mais velhos e empobrecidos - para o desespero de sua mãe) e abandonada por sua psicanalista Ananta Medrado (jovem e virgem - inexperiente, portanto), Rosa busca fugir da decrepitude, mas fracassa. Aliás, o fracasso a tem acompanhado em sua vida pessoal, a despeito do sucesso que foi a sua vida profissional: havia falhado como esposa, como mãe e como amante. Distante dos seus a vida inteira por opção, já sem marido nem filha nem amante nem analista nem parentes nem amigos nem fãs, vê-se solitária, carente e arrependida, mas impotente: não pode mudar o destino que ela tecera para si por décadas (SOUZA; SILVA, 2013, p. 6).

Três protagonistas velhas; três mulheres no mesmo momento da vida, mas com distintas perspectivas sobre sua fase outonal: amarga e rancorosa como Maria Emília, leve e proativa como Maria Leonor ou saudosista e escapista como Rosa Ambrósio. Diferentes facetas para uma mesma realidade: a da finitude que se aproxima de maneira inexorável, causando mudanças de comportamento nas envelhecentes em tela, na tentativa vã de minorar a dor de envelhecerem solitárias e alquebradas.

Somente uma autora como Lygia Fagundes Telles, que com palavras magistralmente escolhidas e uma técnica apurada por mais de oitenta anos de prática, é capaz de captar e sugar a essência de dramas como os vividos por essas três protagonistas, plasmando em forma de palavras essas três concepções distintas para o mesmo foco narrativo, retratando em cada uma dessas personagens a mulher na realidade de seu tempo.

\section{Considerações Finais}

Ao finalizamos esse artigo, reiteramos a importância dessa autora brasileira premiada e que não em vão é tida como o maior exponencial feminino de nossas letras. Dona de uma genialidade lapidada por oito décadas de contribuições literárias massivas e exitosas, Lygia Fagundes Telles eleva-se como uma escritora sensível e visionária, influência para a arte e para a cultura latino-americanas por meio do legado que nos deixa.

Estudar essa autora, discorrer sobre ela, é sempre um exercício de humildade para quem sobre ela investiga cientificamente - tão grande ela é. Muito há o que dissertar acerca dessa 
mulher sempre à frente de seu tempo, inspiradora de todas as gerações de mulheres escritoras que vieram depois dela.

Pesquisar sua vida e sua obra nos faz beber de nossas mais genuínas fontes literárias, possibilitando-nos revisitar o cerne da história da mulher brasileira, do início do século passado ao início deste - com seus labores, suas lutas, seus anseios, seus amores e suas dores que Lygia tão bem sabe entalhar com sua escritura singular e cimentá-la eternizando-a.

Por essas e outras razões, acreditamos que essa autora, dentre todas as nossas grandes, presentes ou já ausentes, é o avatar que melhor nos representa quando o tema é "Ser vidente e ser sensível: mulheres-autoras, arte e cultura na América Latina", sem desmerecer nenhuma, e atendendo ao pedido da própria Lygia: "Me leia enquanto estou quente.".

\section{Referências}

BARTHES, Roland. Linguística e Literatura. São Paulo: Editora 70, 1977.

BESERRA, Luciane. Mosaico do Eu: a construção da identidade nas Horas Nuas de Lygia Fagundes Telles. Dissertação. Orientador: Prof. Dr. Romair Alves de Oliveira. Universidade Federal de Mato Grosso, Instituto de Linguagens, Programa de Pós-Graduação em Estudos de Linguagem, 96 f., Cuiabá - Mato Grosso, 2011 a.

. Resistência e Submissão da Rosa: uma análise do envelhecimento feminino nas Horas Nuas. Revista de Letras Norte@mentos, Estudos Literários, Sinop, v. 4, n. 7, p. 97-108, jan. / jun., $2011 b$.

CÂMARA, Yls Rabelo; CÂMARA, Yzy Maria Rabelo. Lygia Fagundes Telles e a arte de envelhecer: descrevendo a alma feminina em dois de seus contos. Contexto, n. 34, p. 232-258, Vitória, 2018.

FANINI, Michele Asmar. "Como Ficou Chato Ser Moderna, Serei Eterna": Lygia Fagundes Telles, o Feminismo e a Academia Brasileira de Letras. Polêm!ca, v. 9, n. 3, p. 143-160, jul. / set., 2010.

FERREIRA, Josye Gonçalves (2014). Velhice desejante: sexualidade e envelhecimento na ficção de Lygia Fagundes Telles. Dissertação (Mestrado em Letras) - Universidade Estadual de Montes Claros, Montes Claros/MG.

GOMES, Carlos Magno. As Faces da Escritora no Romance de Lygia Fagundes Telles. Errâncias do Imaginário, Porto, p. 55-72, 2015.

LEAL, Joísa Maria de Lima. A Representação da Mulher em Contos de Lygia Fagundes Telles. Monografia de Graduação. Orientadora: Profa. Dra. Virgínia Maria Vasconcelos Leal. Universidade de Brasília, Instituto de Letras, Departamento de Teorias Literárias e Literatura, Licenciatura em Letras/Português, 39 f., 2012. 
LIMA, Susana Moreira de. O corpo feminino reconfigurado: velhice e sexualidade no espaço narrativo. Revista de Letras, v. 2, n. 32, p. 1-11, 2013.

LUCENA, Suênio Campos de. Esquecimento e Lembrança em Lygia Fagundes Telles. Tese. Orientadora: Profa. Dra. Cleusa Rios Pinheiro Passos. Universidade de São Paulo, Faculdade de Filosofia, Letras e Ciências Humanas, Departamento de Teoria Literária e Literatura Comparada, Programa de Pós-graduação em Teoria Literária. 183 f., São Paulo, 2007.

MARTINS, Maria Sárvia da Silva. Mulher e Sociedade: de corpo dominado a corpo dominante em contos de Lygia Fagundes Telles. Dissertação. Orientadora: Profa. Dra. Edilene Ribeiro Batista. Universidade Federal do Ceará, Centro de Humanidades, Departamento de Literatura, Programa de Pós-Graduação em Letras, 108 f., Fortaleza, 2015.

PEDRA, Mabel Knust. Sombra silenciosa. Impotência e solidão em dois contos de Lygia Fagundes Telles. Darantina, v. 1, n. 1, p. 1-15, 2010.

PRAZERES, Lílian Lima Gonçalves dos. Femininos, Identidades e Trânsitos em Narrativas de Clarice Lispector. Dissertação. Universidade Federal do Espírito Santo, Centro de Ciências Humanas e Naturais, Programa de Pós-Graduação em Letras, Vitória, Espírito Santo, 132 p., 2015.

SILVA, Antonia Marly Moura da; MARINHO, Monica Valéria Moraes; SANTOS, Rosaly Ferreira da Costa. A face insólita da morte no conto "Boa noite, Maria", de Lygia Fagundes Telles. Revista Colineares, v. 1, n. 1, p. 87-102, 2014.

SOUZA, Elis Regina Guedes de.; SILVA, Marcelo Medeiros da. A Mulher-Artista em Horas Nuas: o último ato ou a encenação do fracasso da atriz, 10 f., 2013. Acessível em: < http://www.itaporanga.net/genero/4/gt02/08.pdf>. Último Acesso em 30-04-2020.

SOUZA, Nathalia Sobral de. O Envelhecer Feminino: representações literárias sobre a mulher velha. Anais do Fazendo Gênero 9: diásporas, diversidades e deslocamentos, p. 1-8, 2010.

SPERANDIO, Roberta Fresneda Villibor. Leituras da Morte e da Solidão em Maria Judite de Carvalho e Lygia Fagundes Telles. Dissertação. Orientadora: Profa. Dra. Clarice Zamonaro Cortez. Universidade Estadual de Maringá, Centro de Ciências Humanas, Letras e Artes, Programa de Pós-Graduação em Letras, 114 f., 2009.

TELLES, Lygia Fagundes. Seminário dos Ratos - Contos. São Paulo: Companhia das Letras, 1997.

. A Noite Escura e Mais Eu. Companhia das Letras. 1995

As Horas Nuas. São Paulo: Companhia das Letras, 1989.

VIANA, Maria José Amaral. Os (Des) Enredos do Amor: a narrativa do fracasso amoroso em contos de Lygia Fagundes Telles. Dissertação. Orientadora: Profa. Dra. Marlí Tereza Furtado. Universidade Federal do Pará, Instituto de Letras e Comunicação, Curso de Mestrado em Letras, Estudos Literários, 103 f., 2010. 